\title{
Genetic diversity of Bovine Viral Diarrhea Virus from cattle in Chile between 2003 and 2007
}

\author{
Astrid Donoso, Felipe Inostroza, María Celedón and José Pizarro-Lucero* ${ }^{*}$
}

\begin{abstract}
Background: Bovine Viral Diarrhea Virus causes significant economic losses in cattle. BVDV has high genomic diversity, with two species, BVDV-1 and BVDV-2, and at least twenty-one subgenotypes for BVDV-1 and four subgenotypes for BVDV-2. Vaccines are important tools to reduce the economic losses caused by this virus. However, vaccine strains must correspond to the antigenic profile of the viruses present in the region where the vaccine is applied. A restricted phylogenetic study with 14 viruses isolated from cattle between 1993 and 2001 showed that the genetic profile of BVDV in Chile consisted of viruses of both species and sub-genotypes 1a, 1b, 1c (currently $1 \mathrm{j}$ ) and $2 \mathrm{a}$. To determine more accurately the genetic profile of BVDV in Chile, in this study a larger number of viruses obtained from bovines between 2003 and 2007 were typed.

Results: The study was performed using partial sequences from the $5^{\prime}$ noncoding region ( $\left.5^{\prime} \mathrm{UTR}\right)$ and $\mathrm{E} 2$ coding region of the viral genome of thirty-five Chilean viruses isolated from geographic regions that have $84.6 \%$ of the Chilean cattle. All tested viruses belonged to species BVDV-1. Eighteen viruses belonged to BVDV-1j subgenotype (51.4\%), twelve belonged to BVDV-1b (34.3\%) and five belonged to BVDV-1a (14.3\%). The Chilean BVDV-1j viruses showed low genetic diversity, both among themselves and with the BVDV-1j present in other regions of the world. This could be explained by a relatively recent introduction of this viral subgenotype in cattle, which agrees with its low geographical distribution worldwide. Otherwise, Chilean BVDV-1b viruses grouped into a single cluster, different even than the viruses present in Argentina and Brazil, countries geographically close to Chile, a process of local evolution that could generate antigenic differences between the Chilean viruses and the viruses used as vaccine strains.

Conclusions: The high presence of viruses of the BVDV-1j subgenotype, which show major antigenic differences with BVDV-1a and BVDV-1b subgenotypes used in the commercial vaccines, suggest that BVDV-1j viruses could be an emergent subgenotype of BVDV in cattle in South America and suggest evaluating an update of the vaccines used in Chile.
\end{abstract}

Keywords: Bovine viral diarrhea virus, Pestivirus, BVDV, Genetic diversity, 5'UTR, E2

\section{Background}

The Bovine Viral Diarrhea Virus (BVDV) is a virus of worldwide distribution, which causes a wide variety of clinical symptoms in cattle, being recognized as the viral agent that causes the main economic losses in the global cattle industry $[1,2]$.

\footnotetext{
* Correspondence: jpizarro@uchile.cl
Laboratory of Animal Virology, Department of Animal Preventive Medicine,
Faculty of Livestock and Veterinary Sciences, University of Chile, Av. Santa

* Correspondence: jpizarro@uchile.cl
Laboratory of Animal Virology, Department of Animal Preventive Medicine, Faculty of Livestock and Veterinary Sciences, University of Chile, Av. Santa

Rosa, 11735 Santiago, Chile
}

(c) The Author(s). 2018 Open Access This article is distributed under the terms of the Creative Commons Attribution 4.0 International License (http://creativecommons.org/licenses/by/4.0/), which permits unrestricted use, distribution, and reproduction in any medium, provided you give appropriate credit to the original author(s) and the source, provide a link to the Creative Commons license, and indicate if changes were made. The Creative Commons Public Domain Dedication waiver (http://creativecommons.org/publicdomain/zero/1.0/) applies to the data made available in this article, unless otherwise stated. ciated with respiratory and gastrointestinal diseases of different severity, hemorrhagic syndrome, and reproductive problems, such as infertility. BVDV also causes immunosuppression, which increases the severity of diseases caused by other pathogens. The virus is able to cross the placenta infecting the fetus, causing embryonic reabsorption, fetal mummification, abortion and congenital malformations, especially of the central nervous system. Fetal infection with a non-cytopathic virus in the first trimester of pregnancy causes persistently infected 
animals with BVDV (PI), which are the main source of infection of susceptible animals in the herd. Superinfection of PI animals with a cytopathic BVD virus very close antigenically with the non-cytopathic BVD virus produces the fatal bovine viral diarrhea-mucosal disease (BVD-MD) [3-6].

Bovine Viral Diarrhea Virus (BVDV) is a member of the genus Pestivirus, family Flaviviridae, which includes four specie: Bovine Viral Diarrhea Virus 1 (BVDV-1), Bovine Viral Diarrhea Virus 2 (BVDV-2), Classical Swine Fever Virus and Border Disease Virus [7]. The genome of BVDV is a single-stranded RNA of positive polarity, approximately $12.3 \mathrm{~Kb}$ in length. The genome contains a single open reading frame that encodes 11-12 viral proteins, flanked by a 5 'and 3' untranslated region [7]. Genetic typing has classified the BVDV isolates into two species, Bovine Viral Diarrhea Virus 1 (BVDV-1) and Bovine Viral Diarrhea Virus 2 (BVDV-2), with at least 21 subgenotypes of BVDV-1 (1a-1u) and four subgenotypes of BVDV-2 (2a-2d) [7-14]. BVDV-2 strains were initially isolated from acute hemorrhagic disease outbreaks in North America, but later it could be established that both viral species of BVDV cause similar clinical symptoms. BVDV-1 strains are distributed worldwide, while the BVDV-2 strains are present mainly in the United States, Canada and South America, with few reports of their presence in Europe and Japan [10, 15-20]. Recently, an atypical pestivirus (HoBi-like) isolated from cattle and water buffaloes has been proposed as a new species (BVDV-3) based on phylogenetic analyzes [8, 21].

BVDV infection is widespread among Chilean cattle, with a serological prevalence ranging from 59.7 to $69.2 \%$ in unvaccinated animals from different regions of the country $[22,23]$. To design an effective vaccination strategy against the BVDV virus in Chile, the vaccine strains must match the genetic profile of the viruses that infect Chilean cattle for optimal protection [24, 25]. In 2006, a phylogenetic study with 14 viruses isolated from cattle between 1993 and 2001 showed that the genetic profile of BVDV in Chile consisted of viruses of both species and subgenotypes 1a, 1b, 1c (currently 1j) and 2a, with a high prevalence of sub-type $1 \mathrm{~b}(42.9 \%)$ [20]. The objective of this study was to determine more precisely the genetic profile of BVDV in Chile, with a greater number of viruses obtained from bovines between 2003 and 2007.

\section{Methods}

\section{Samples}

The thirty-five viruses included in this study were obtained from sera of calves and adult cattle and tissue of bovine fetuses from different regions of central and southern Chile from 2003 to 2007. Twenty-five viruses were isolated from sera of asymptomatic calves and adult cattle or those suffering enteric, respiratory or reproductive problems in the Metropolitana, Maule, Bio-Bio, Araucanía, De Los Rios and De Los Lagos Regions, which have $84.6 \%$ of the Chilean cattle [26]. Ten viruses were isolated from organ suspensions of bovine fetuses in the Metropolitana and Araucanía Regions. The list of the BVDV viruses examined in this study is shown in Table 1.

The viruses were propagated on monolayers of MDBK cells line (ATCC CCL-22), determined to be free of BVDV and grown in Eagle's Minimum Essential Medium supplemented with $10 \%$ equine serum. All infections were monitored by direct immunofluorescence (DIF) assay. DIF was performed in acetone-fixed cells, using a FITC-conjugated anti-BVDV polyclonal serum (Central Veterinary Laboratory, Addlestone, Surrey, UK). All viruses were of the non-cytopathic biotype.

\section{Primers}

The 5'UTR region corresponding to positions 108 to 395 according to the NADL genome sequence was amplified using the panpestivirus-specific primers 324/326 [27]. This pair of primers is highly sensitive for BVDV-1 and BVDV-2 viruses, but it is less sensitive for HoBi-like viruses, which may limit the detection of Hobi-like viruses in this study [21].

To confirm the data in 5'UTR, a 700 bp DNA fragment corresponding to positions 2754 to 3453 of the E2 region, according to the NADL genome sequence, was amplified with the primers E2F (5'-ACTTTGAAT TTGGACTYTGCC-3', nucleotides 2754-2774 of the NADL genome) and E2R (5'-TCCAGGTCAAACCARTATTG-3', nucleotides 3453-3434 of the NADL genome) for selected viruses.

\section{RT-PCR}

Total RNA was obtained from infected cells using Trizol LS (Invitrogen) according to the manufacturer's instructions. The RNA was suspended in $50 \mu$ DEPC-treated water. Amplification of viral RNA by RT-PCR was carried out in a SuperScript III One-Step RT-PCR System with Platinum Taq DNA Polymerase (Invitrogen), according to the manufacturer's instructions, under the following conditions: 1) 5'-UTR Region: $12.5 \mu \mathrm{l} \mathrm{2x}$ Reaction Mix, $0.2 \mathrm{mM}$ dNTP, $2 \mathrm{mM} \mathrm{MgSO}_{4}, 10 \mathrm{pmol}$ each primer 324 and 326, $5 \mu$ heat-denatured RNA $\left(2 \mathrm{~min}\right.$ at $\left.94{ }^{\circ} \mathrm{C}\right)$, and $1 \mu \mathrm{l}$ SuperScript III RT / Platinum Taq Mix. Synthesis of cDNA was performed in $25 \mu \mathrm{l}$ final volume for $30 \mathrm{~min}$ at $55^{\circ} \mathrm{C}$. After reverse transcription, the reaction was heated in a thermocycler for $3 \mathrm{~min}$ at $94{ }^{\circ} \mathrm{C}$ and then submitted to 30 cycles of amplification. The amplification conditions were $30 \mathrm{~s}$ at $94{ }^{\circ} \mathrm{C}$, $1 \mathrm{~min}$ at $55^{\circ} \mathrm{C}$ and $1 \mathrm{~min}$ at $68^{\circ} \mathrm{C}$. 2) E2 Region: $12.5 \mu \mathrm{l}$ 2x Reaction Mix, $0.2 \mathrm{mM}$ dNTP, $1.6 \mathrm{mM} \mathrm{MgSO}_{4}$, 10 pmol each primer E2F and E2R, $5 \mu$ l heat-denatured 
Table 1 Chilean BVDV field isolates studied in this work

\begin{tabular}{|c|c|c|c|c|c|c|c|}
\hline \multirow[t]{2}{*}{ Isolate } & \multirow[t]{2}{*}{ Year } & \multirow[t]{2}{*}{ Sample } & \multirow[t]{2}{*}{ Region } & \multirow[t]{2}{*}{ Clinical symptoms } & \multicolumn{2}{|c|}{ Accession number } & \multirow[t]{2}{*}{ Type } \\
\hline & & & & & $5^{\prime} \mathrm{UTR}$ & E2 & \\
\hline $\mathrm{CHL} / 914$ & 2005 & LN & Araucanía & Abortion & JF759955 & JF776638 & BVDV-1b \\
\hline $\mathrm{CHL} / 916$ & 2003 & Serum & de los Ríos & PI & JF759940 & JF776639 & BVDV-1a \\
\hline $\mathrm{CHL} / 917$ & 2003 & Serum & de los Lagos & $\mathrm{Pl}$ & JF759946 & $J F 776640$ & BVDV-1b \\
\hline CHL/918 & 2003 & Serum & de los Lagos & PI & JF759944 & JF776641 & BVDV-1b \\
\hline CHL/919 & 2003 & Serum & de los Lagos & $\mathrm{Pl}$ & JF759945 & JF776642 & BVDV-1b \\
\hline CHL/920 & 2003 & Serum & de los Lagos & $\mathrm{Pl}$ & JF759947 & JF776643 & BVDV-1b \\
\hline CHL/921 & 2003 & Serum & de los Lagos & $\mathrm{Pl}$ & JF759941 & JF776644 & BVDV-1a \\
\hline $\mathrm{CHL} / 927$ & 2006 & Serum & Bío-Bío & $\mathrm{RD}$ & JF759926 & MH078039 & BVDV-1j \\
\hline CHL/928 & 2006 & Serum & Bío-Bío & $\mathrm{RD}$ & JF759932 & MH078040 & BVDV-1j \\
\hline CHL/939 & 2006 & Serum & Bío-Bío & $\mathrm{RD}$ & JF759931 & - & BVDV-1j \\
\hline $\mathrm{CHL} / 958$ & 2006 & Serum & Bío-Bío & $\mathrm{RD}$ & JF759928 & MH078041 & BVDV-1j \\
\hline $\mathrm{CHL} / 971$ & 2006 & Serum & Bío-Bío & $\mathrm{RD}$ & JF759937 & - & BVDV-1j \\
\hline $\mathrm{CHL} / 972$ & 2006 & Serum & Bío-Bío & $\mathrm{RD}$ & JF759930 & MH078042 & BVDV-1j \\
\hline CHL/992 & 2006 & Serum & Bío-Bío & $\mathrm{RD}$ & JF759956 & MH078043 & BVDV-1j \\
\hline $\mathrm{CHL} / 1014$ & 2006 & Serum & Bío-Bío & $\mathrm{RD}$ & JF759929 & - & BVDV-1j \\
\hline $\mathrm{CHL} / 1025$ & 2007 & Serum & Metropolitana & $\mathrm{RD}$ & JF759948 & JF776645 & BVDV-1b \\
\hline $\mathrm{CHL} / 1061$ & 2007 & Serum & Metropolitana & $\mathrm{RD}$ & JF759949 & - & BVDV-1b \\
\hline CHL/1068 & 2007 & Serum & Metropolitana & $\mathrm{RD}$ & JF759942 & JF776646 & BVDV-1a \\
\hline CHL/1071 & 2003 & Serum & Araucanía & Diarrhea & JF759950 & - & BVDV-1b \\
\hline $\mathrm{CHL} / 1076$ & 2007 & Serum & Araucanía & None & JF759951 & - & BVDV-1b \\
\hline CHL/1078 & 2007 & Serum & Araucanía & Abortion & JF759936 & MH078044 & BVDV-1j \\
\hline $\mathrm{CHL} / 1086$ & 2007 & Serum & Araucanía & None & JF759954 & - & BVDV-1b \\
\hline CHL/1087 & 2007 & Serum & Maule & None & JF759935 & MH078045 & BVDV-1j \\
\hline $\mathrm{CHL} / 1091$ & 2007 & Serum & Bío-Bío & None & JF759922 & JF776648 & BVDV-1a \\
\hline CHL/1092 & 2007 & Serum & Maule & Abortion & JF759952 & - & BVDV-1b \\
\hline $\mathrm{CHL} / 1109$ & 2007 & Serum & Bío-Bío & None & JF759953 & - & BVDV-1b \\
\hline CHL/P22 & 2006 & Lung & Metropolitana & None & JF759923 & - & BVDV-1j \\
\hline CHL/P23 & 2006 & Lung & Metropolitana & None & JF759927 & - & BVDV-1j \\
\hline $\mathrm{CHL} / \mathrm{P} 24$ & 2006 & Lung & Metropolitana & None & JF759934 & - & BVDV-1j \\
\hline $\mathrm{CHL} / \mathrm{P} 26$ & 2006 & Lung & Metropolitana & None & JF759938 & - & BVDV-1j \\
\hline CHL/P28 & 2006 & Lung & Metropolitana & None & JF759943 & - & BVDV-1a \\
\hline CHL/P30 & 2006 & Lung & Metropolitana & None & JF759939 & MH078046 & BVDV-1j \\
\hline CHL/P31 & 2006 & Lung & Metropolitana & None & JF759933 & - & BVDV-1j \\
\hline CHL/P32 & 2006 & Lung & Metropolitana & None & JF759924 & - & BVDV-1j \\
\hline CHL/P33 & 2006 & Lung & Metropolitana & None & JF759925 & - & BVDV-1j \\
\hline
\end{tabular}

LN Lymph Node, PI Persistent Infection, RD Reproductive Disorder

RNA ( 2 min at $94{ }^{\circ} \mathrm{C}$ ), and $1 \mu \mathrm{l}$ SuperScript III RT/Platinum Taq Mix. Synthesis of cDNA was performed in $25 \mu \mathrm{l}$ final volume for $30 \mathrm{~min}$ at $50{ }^{\circ} \mathrm{C}$. After reverse transcription, the reaction was heated in a thermocycler for $3 \mathrm{~min}$ at $94{ }^{\circ} \mathrm{C}$ and then submitted to 30 cycles of amplification. The amplification conditions were $30 \mathrm{~s}$ at $94{ }^{\circ} \mathrm{C}, 1 \mathrm{~min}$ at $50{ }^{\circ} \mathrm{C}$ and $1 \mathrm{~min}$ at $68{ }^{\circ} \mathrm{C}$. Amplified products were visualized by electrophoresis in $2 \%$ agarose gel run in $90 \mathrm{mM}$ Tris, $90 \mathrm{mM}$ boric acid, $2 \mathrm{mM}$ EDTA at $18 \mathrm{~V} / \mathrm{cm}$ of gel and stained with ethidium bromide.

\section{Genes sequencing and genetic analysis}

The amplified products were purified using the QIAquick PCR purification kit (Qiagen) and DNA sequencing was performed on an ABI-310 automated sequencer using 
dideoxy-sequencing chemistry utilizing the Big Dye Terminator Cycle Sequencing with Ampli Taq DNA polymerase (Applied Biosystems). Both strands of each PCR product were sequenced in triplicate from amplified products obtained from individual amplifications.

Phylogenetic reconstructions for genetic typing were compiled using a 230 nucleotide region of the 5-UTR (nucleotides 142-371 of the NADL genome) and a 420 nucleotide region of E2 (nucleotides 2879-3298 of the NADL genome). Nucleotide sequences from representative isolates of previously identified phylogenetic groups of BVDV were included in the phylogenetic analysis.

The nucleotide sequences obtained from each region were aligned using the MUSCLE program [28], then a matrix of distances for Kimura's two-parameter model was generated, and the phylogenetic analysis was performed using the maximum likelihood method from the MEGA version 7 program [29]. The robustness of the phylogenetic analysis and significance of the branching order were determined by a bootstrap analysis carried out on 1000 replicates, which showed only bootstrap values of $\geq 50 \%$. Sequence Demarcation Tool (SDT) v1.2 software was used to calculate pairwise identities using MUSCLE alignments for E2 nucleotide sequences of some viruses [30], and shown in matrix format. To analyze the differences at the molecular level of the E2 glycoprotein of the Chilean BVDV isolates with viruses of BVDV-1a, BVDV-1b and BVDV-1j subgenotypes from Argentina, Brazil and other regions of the world, the deduced amino acid sequences were aligned using MUSCLE and the pattern of amino acid substitutions near Domain C (amino acids 843 to 870), an important antigenic site of BVDV, was analyzed.

\section{Results}

The 5'UTR phylogenetic tree was constructed using the nucleotide sequences of the 35 Chilean BVDV viruses of this study and BVDV reference strains from GenBank (Fig. 1). The accession numbers of the sequences obtained during this study are given in Table 1 .

On the basis of phylogenetic analysis of 5'UTR, all 35 BVDV isolates belonged to species BVDV-1. The percentage identities (PID) among all the Chilean BVDV-1 viruses were $88-100 \%$. Eighteen Chilean viruses grouped in the BVDV-1j subgenotype (51.4\%), at a confidence level of $98 \%$ by bootstrap analysis. The PID among the Chilean BVDV-1j viruses were 97-100\%. The BVDV-1j subgenotype was subdivided into two clusters. All the Chilean viruses grouped together with the Argentinean isolates $2 \mathrm{~B}$ and $17 \mathrm{P}$ (cluster $1 \mathrm{j}$-SAM). The other cluster was composed of BVDV-1j viruses isolated in Europe, Africa and Asia (cluster $1 \mathrm{j}$-INT). Twelve Chilean viruses grouped in BVDV-1b subgenotype (34.3\%), at a confidence level of $78 \%$ by bootstrap analysis. The PID among the Chilean BVDV-1b viruses were 96-100\%. This subgenotype was subdivided into two clusters. All the Chilean viruses of this study were grouped with the viruses $\mathrm{CHL} / 113, \mathrm{CHL} / 170, \mathrm{CHL} / 226, \mathrm{CHL} / 481$ and CHL/615, also isolated from bovines in Chile [20], and the CHL/Pudu/Zoo isolated from pudú (Pudu puda), an indigenous deer of Chile from a Chilean Zoo, [31], forming a cluster only with Chilean viruses (cluster $1 \mathrm{~b}-\mathrm{CHL}$ ). By contrast, the Chilean BVDV-1b viruses CHL/184, CHL/379, CHL/565 [20] and the CHL/Pudu-Chillan isolated from a free-ranging pudú [32] grouped in a different cluster with BVDV-1b viruses from other regions of the world (European, American, Argentinean, Brazilian) (cluster 1b-INT). Five Chilean viruses grouped in the BVDV-1a subgenotype (14.3\%) with PID among them of $92-100 \%$. The CHL/1091 virus showed a sequence identity of $100 \%$ with the NADL strain in the analyzed region of 5'UTR. There was no obvious association of any subgenotype with geographical location.

To confirm the phylogenetic analysis obtained with the 5'UTR region, E2 genes of eighteen Chilean viruses of this study belonging to the different subgenotypes were sequenced, and the E2 phylogenetic tree was constructed using the nucleotide sequences of BVDV reference strains from GenBank (Fig. 2). The accession numbers of the sequences obtained are given in Table 1.

The results obtained with the E2 phylogenetic analysis showed the same classification as that observed using the 5'UTR nucleotide sequences, with the viruses conserving their type. The Chilean BVDV-1j, BVDV-1b, and BVDV-1a viruses grouped at a confidence level of $99 \%$, 99\%, and $78 \%$, respectively, by bootstrap analysis. Chilean BVDV-1b viruses were grouped in a cluster only with Chilean viruses (cluster 1b-CHL) clearly apart from Brazilian and Argentinean viruses, with bootstrap values of $99 \%$ and $68 \%$, respectively.

The pairwise identity matrix of selected E2 nucleotide sequences was calculated using SDT v1.2 software (Fig. 3). The matrix showed that the sequence identity among the Chilean BVDV-1a viruses isolated in this study ranged from 87 to $100 \%$, between the Chilean BVDV-1b viruses ranged from 93 to $100 \%$, and between the Chilean BVDV-1j viruses ranged from 98 to $100 \%$. The sequence identity of BVDV-1j viruses, when viruses from other regions of the world were included (KS86ncp, 190CP and Deer-GB1), ranged between 97 and $100 \%$. The sequence identity between the Chilean BVDV-1b viruses with the Brazilian BVDV-1b viruses ranged from 83 to $86 \%$, and the sequence identity between the Chilean BVDV-1b viruses and the Argentinean BVDV-1b viruses ranged from 81 to $86 \%$.

To analyze the differences of the E2 glycoprotein of the Chilean isolates at the molecular level, the deduced amino acid sequences were aligned and the substitution 


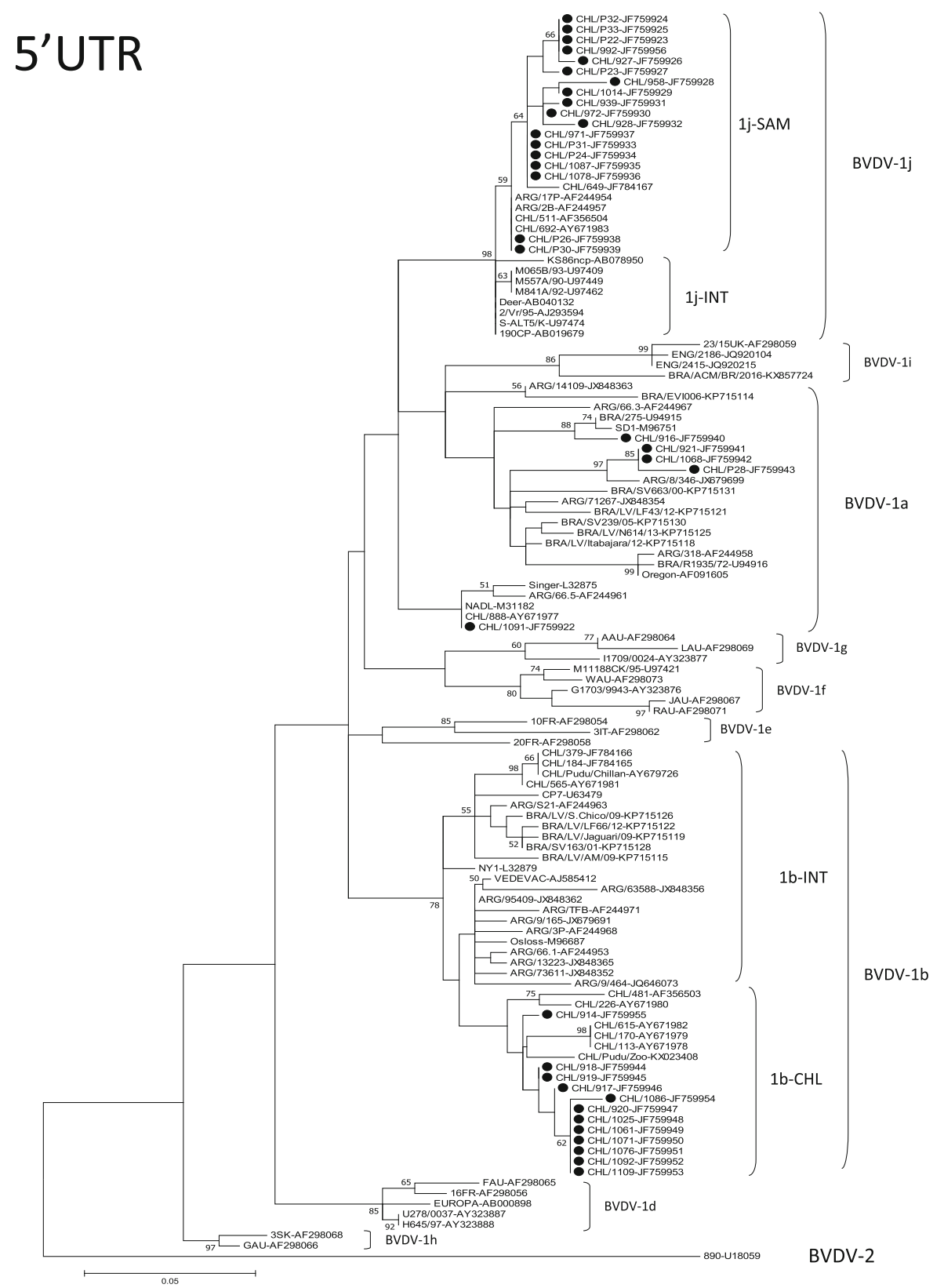

Fig. 1 Phylogenetic analysis of Chilean BVDV isolates based on partial 5'-Untranslated Region (5'UTR). The phylogenetic tree were prepared using the Maximum Likelihood method and numbers over branches indicate the percentage of 1000 bootstrap replicates that support each phylogenetic branch. The GenBak accession numbers are indicated after the name of the BVDV strains. The Chilean viruses of this study are marked with circles

patterns in or near Domain $\mathrm{C}$ (nDomC), an important antigenic region of BVDV located between amino acid positions 843 and 870 of the NADL polyprotein sequence were analyzed (Fig. 4).

The pattern of amino acid substitutions (PAAS) showed that viruses BVDV/1091, BVDV/921 and BVDV/1068 had the same amino acid sequences in Domain $\mathrm{C}$, and zero or one amino acid substitution in the $\mathrm{nDomC}$ of the E2 protein, but these viruses showed three amino acid substitutions in Domain $\mathrm{C}$ and seven or eight amino acid substitutions in the $\mathrm{nDomC}$ of the E2 protein with respect to the BVDV/916 strain. The PAAS between the Chilean BVDV-1b viruses of this study showed zero or three amino acid substitutions in Domain $\mathrm{C}$, and between zero and five amino acid substitutions in the $\mathrm{nDomC}$ of the $\mathrm{E} 2$ protein. The PAAS between the Chilean and Brazilian BVDV-1b viruses showed eight or ten amino acid substitutions in the 


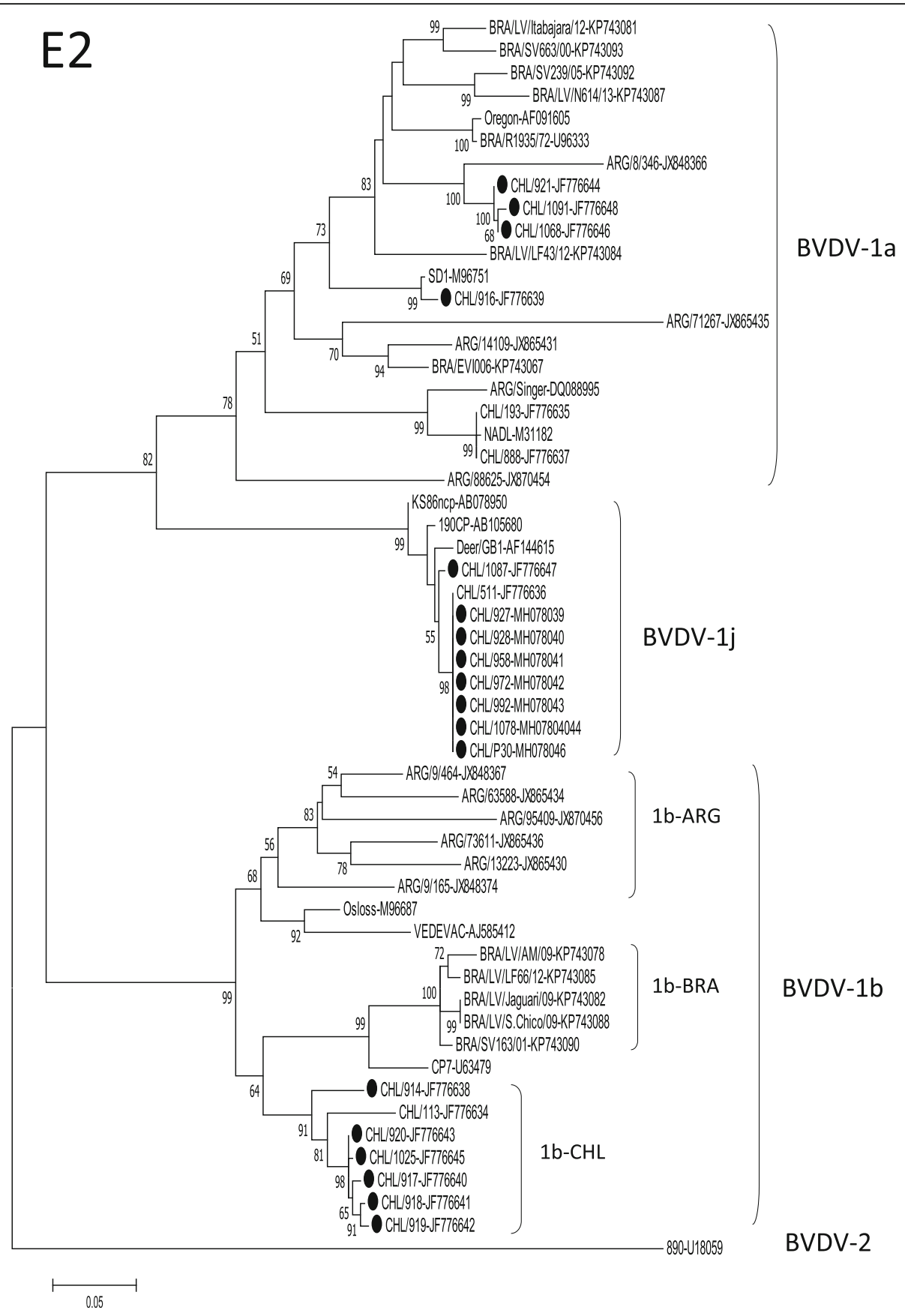

Fig. 2 Phylogenetic analysis of Chilean BVDV isolates based on partial E2 coding region (E2). The phylogenetic tree was prepared using the Maximum Likelihood method and numbers over branches indicate the percentage of 1000 bootstrap replicates that support each phylogenetic branch. The GenBak accession numbers are after the name of the BVDV strains. The Chilean viruses of this study are marked with circles

$\mathrm{nDomC}$, and seven to sixteen amino acid substitutions in the $\mathrm{nDomC}$ between the Chilean and Argentinean BVDV-1b viruses. The PAAS between the Chilean BVDV-1j viruses of this study showed zero or one amino acid substitutions in Domain $\mathrm{C}$, and between zero and three amino acid substitutions in the $\mathrm{nDomC}$ of the E2 protein, and the PAAS between the Chilean BVDV-1j viruses and BVDV-1j viruses from other countries was also very similar, with zero to two amino acid substitutions in Domain $C$, and between zero and five amino acid substitutions in the $\mathrm{nDomC}$ of the E2 protein.

\section{Discussion}

Bovine Viral Diarrhea Virus is widely spread in Chilean cattle, with a serological prevalence ranging from 59.7 to $69.2 \%$ [22, 23], and although an official control of BVDV 

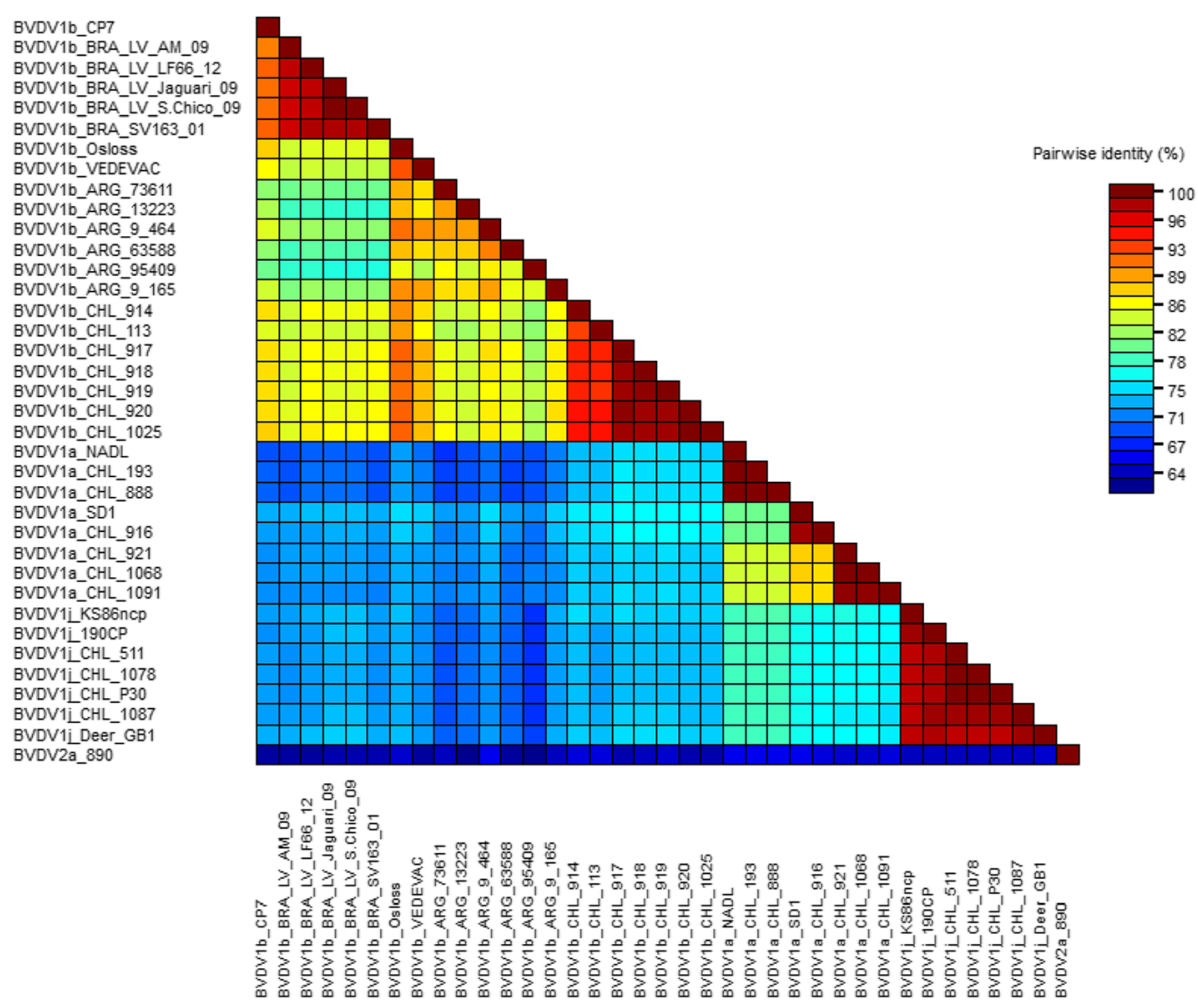

Fig. 3 SDT matrix of pairwise identity scores generated by alignment of a 420 bp fragment of the E2 gene for 37 BVDV viruses. Each colored cell represents the percentage of identity between two nucleotide sequences, one horizontally and the other vertically, that intersect in the cell. $\mathrm{A}$ figure indicating the correspondence between pairwise identities and the colors is included

is not applied in Chile many farmers are using vaccines in order to reduce economic losses. Nevertheless, an effective vaccination strategy against BVDV requires that vaccines reflect the genetic and antigenic types of viruses that infect Chilean cattle.

A survey of the genetic diversity of 35 field isolates infecting cattle in Chile between 2003 and 2007 was conducted by determining the nucleotide sequences of the 5'-UTR. The results showed that three subgenotypes were circulating in Chilean cattle: BVDV-1a (5/35; 14.3\%), BVDV-1b (12/35; 34.3\%), and BVDV-1j (18/35; $51.4 \%)$, with BVDV-1b and BVDV- $1 j$ as the predominant subgenotypes. Surprisingly, BVDV-2 was not detected, even though it had been previously detected in Chile [20]. In the study published by Pizarro-Lucero in 2006 [20], phylogenetic analysis from 14 isolates obtained between 1993 and 2001 showed the presence of viruses belonging to subgenotypes BVDV-1a (1/14; 7.1\%), BVDV-1b (6/14; 42.9\%), BVDV-1c (currently classified as BVDV-1j viruses) $(2 / 14 ; 14.3 \%)$ and BVDV-2a (5/14; $35.7 \%)$.

The results of this study showed that the genetic composition of BVDV viruses infecting cattle in Chile has changed over the years. The BVDV-1b subgenotype has been maintained as a predominant subgenotype in the Chilean cattle, and the subgenotype BVDV-1a is present in low number. Nevertheless, BVDV-1j viruses were isolated more frequently in the samples obtained between 2003 and 2007 (51.4\%) in comparison with the samples isolated between 1993 and 2001 (14.3\%), and BVDV-2 was not circulating in Chilean cattle, or is present in a very low number that was not detected in this study. Furthermore, considering that all the BVDV- $1 j$ viruses analyzed except for African isolate M1515A/90 have lost the restriction site for the Xho I enzyme (data not shown), only 2/33 viruses isolated between 1993 and 2001 in Chile belonged to subgenotype BVDV1j (6.1\%).

These differences could be a result of immune selection, because it has been described that BVDV- $1 j$ viruses showed significant antigenic differences with BVDV-1a and BVDV-1b viruses, mainly used as vaccine strains $[12,20,33]$. In this study, nine of eighteen BVDV-1j viruses were isolated from cattle showing reproductive problems, but the pathogenicity of the BVDV- $1 j$ subgenotype was not clear yet. Otherwise, the high similarity shown between the Chilean and Argentinean BVDV-1j viruses (cluster 1j-SAM) suggests a common ancestor for these viruses. The non-obvious association of any subgenotype with geographical location was expected due to the absence of a national control program that 


\section{Domain C 870}

\begin{tabular}{|c|c|}
\hline & \\
\hline & CMLANRDTLDTAWVRTYRRSVPFPYRQGCITQKTLGEDLYDCALGGNWTCVTGDQSRYT \\
\hline NADL & 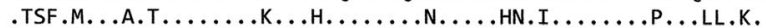 \\
\hline SINGER & 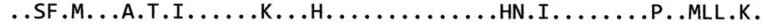 \\
\hline ARG/88625 & 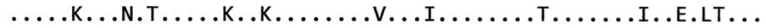 \\
\hline ARG/71267 & 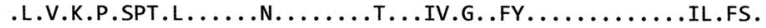 \\
\hline ARG/14109 & ........ \\
\hline ARG/8/346 & 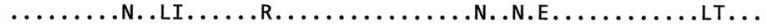 \\
\hline BRA/EVI006 & 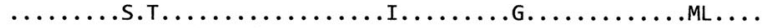 \\
\hline BRA/LV/LF43/12 & $\ldots \ldots \ldots \ldots \ldots,{ }_{\text {V.T.QK. }} \ldots \ldots \ldots \ldots \ldots$ \\
\hline BRA/SV663/00 & 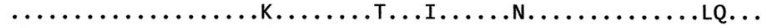 \\
\hline BRA/SV239/05 & 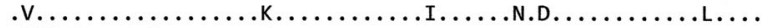 \\
\hline $\mathrm{CHL} / 888$ & 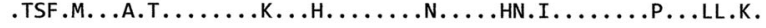 \\
\hline $\mathrm{CHL} / 916$ & $\cdots \cdots \cdots \cdots \cdots$ \\
\hline $\mathrm{CHL} / 921$ & $\ldots \ldots \ldots \ldots \ldots$ IQ......... \\
\hline $\mathrm{CHL} / 1068$ & $\ldots \ldots \ldots \ldots \ldots$ IQ $\ldots \ldots$ R.... \\
\hline L/1091 & 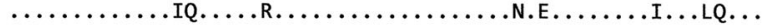 \\
\hline
\end{tabular}

CP7 BVDV1b

Osloss

VEDEVAC

ARG/13223

ARG $/ 63588$

ARG/73611

ARG/95409

ARG/9/165

ARG/9/464

BRA/LV/AM/O9

BRA/LV/LF66/12

BRA/LV/Jaguari/09

BRA/LV/S.Chico/09

BRA/SV163/01

$\mathrm{CHL} / 113$

$\mathrm{CHL} / 914$

$\mathrm{CHL} / 917$

$\mathrm{CHL} / 918$

CHL/919

$\mathrm{CHL} / 920$

$\mathrm{CHL} / 1025$

190cp BVDV1j

KS86ncp

Deer-GB1

CHL/511

$\mathrm{CHL} / 958$

$\mathrm{CHL} / 992$

$\mathrm{CHL} / 1078$

$\mathrm{CHL} / 1087$

CHL/P30

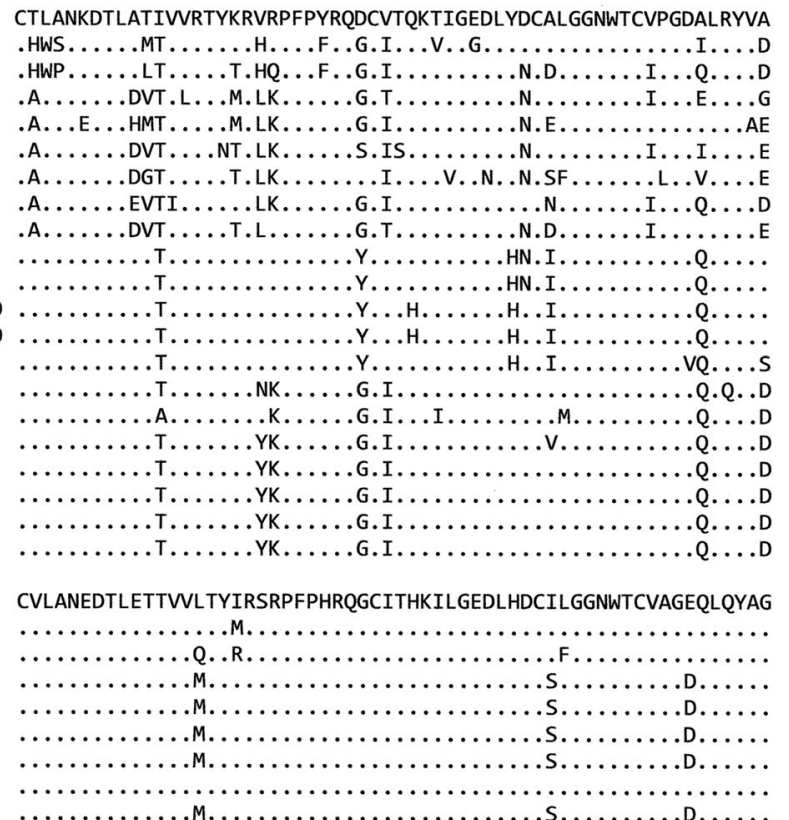

Fig. 4 Alignment of partial amino acid sequences of E2 of BVDV-1a, BVDV-1b and BVDV-1j subgenotypes of BVDV. The aligned sequences correspond to amino acids from 832 to 891 . Dots represent identical amino acids to the standard sequence of the corresponding subgenotype (BVDV-1a: SD-1, BVDV-1b: CP7, and BVDV-1j: 190cp). Uppercase letters represent an amino acid substitution. Domain C (amino acids 843 to 870) is indicated

could limit the free movement of the BVDV infected animals around the country.

The E2 phylogenetic analysis showed the same typing obtained with the 5'UTR region. Analyzing the phylogenetic tree of E2 (Fig. 2) and the sequence identity of the viruses of the subgenotypes present in Chile (Fig. 3), three different situations can be observed: a) the Chilean BVDV-1a viruses showed greater genetic diversity between them than the viruses of the other subgenotypes. This may be explained by continuous reintroductions of these viruses to national cattle, probably through commercial vaccines, since the viral strains NADL and SD-1 are frequently used as vaccine strains; b) the Chilean BVDV-1j viruses showed low genetic diversity both among themselves and with the BVDV-1j present in other regions of the world, which is expressed in a relatively compact cluster of these viruses in the phylogenetic tree and high sequence identity between them. This low genetic diversity in the most variable protein of the virus between strains isolated from such diverse regions of the world (Chile, Japan, United Kingdom) could be explained by a relatively recent introduction of this viral subgenotype in cattle, which agrees with its low geographic distribution worldwide; and c) the Chilean BVDV-1b viruses of this study grouped into a single cluster, different even from viruses genetically representatives of the viruses that had been circulating in similar period of time in Argentina and Brazil (2001-2009 and 20062010 , respectively) $[34,35]$, countries geographically close to Chile. These results could be explained by the presence of BVDV-1b viruses in the Chilean cattle for a long period of time, which would have allowed a process of local 
evolution. This process of local evolution could generate important antigenic differences between viruses of the BVDV-1b subgenotype but with different evolutionary histories, as reported by Pecora et al., 2014 [34]. This suggests performing studies on the antigenic diversity of the BVDV-1b viruses present in different regions of the world and evaluating the relevance of generating vaccines with local strains of this viral subgenotype.

The pattern of amino acid substitutions in or near Domain $\mathrm{C}(\mathrm{nDomC})$ in the E2 region of Chilean viruses of the different subgenotypes showed that most amino acid changes occurred in the same positions, and usually with the same amino acids in viruses of equal subgenotype (Fig. 4).

The Chilean BVDV-1a viruses BVDV/921, BVDV/1068 and BVDV/1091 showed a very similar amino acid sequence, and larger differences with BVDV/916, that showed an identical amino acid sequence with the SD-1 strain. This is similar to the CHL/888 strain that showed identical amino acid sequence with the NADL strain. These results support those observed with molecular phylogeny and pairwise identity matrix, that some of these viruses can be the result of isolation of vaccine strains. The Chilean BVDV-1b viruses showed a very similar amino acid sequence among them and with the viral strain CP7 (USA), and clearly different with the Brazilian BVDV-1b viruses (obtained between 2001 and 2012) and the Argentinean BVDV-1b viruses (obtained between 2006 and 2010). This high variability in and near Domain $C$, an important antigenic region of BVDV in E2, the immunodominant protein of BVDV, could cause important changes in the antigenicity of these viruses. The Chilean BVDV- $1 \mathrm{j}$ viruses showed very similar amino acid sequences between them, and also with BVDV-1j viruses not present in Chile (KS86, 190CP and Deer-GB), but clearly different than the viruses that belong to BVDV-1a and BVDV-1b subgenotypes. These results supports those shown previously, that BVDV- $1 j$ viruses have very similar antigenicity between them, but have important antigenic differences with viruses of the BVDV-1a, BVDV-1b and BVDV-2 subgenotypes [12, 20,33].

The results of this study showed that the genetic profile of the BVDV viruses prevalent in Chile is quite different from the virus diversity reported in South America, Europe and North America [9, 17, 34-42]. The high presence of viruses that belong to subgenotype BVDV- $1 j$ in Chile and the increase shown over time makes a significant difference with the genetic profile of the virus reported in other countries of the world, including South America, that lead us to consider viruses of the BVDV- $1 j$ subgenotype as a possible emergent group of BVDV viruses in cattle.

Although an official control of BVDV is not yet applied in Chile, vaccines are used in many farms, and the current commercial BVDV vaccines are mainly based on BVDV-1a, BVDV-1b or BVDV-2a strains. Nevertheless, although all BVDVs share epitopes of a common pestiviral antigen, antigenic differences have been demonstrated among BVDV types [43], and this is particularly true between BVDV-1a/BVDV-1b and BVDV-1j strains, which have shown major antigenic differences [12, 20,33].

Further studies should be done to assess if the predominance of BVDV- $1 j$ strains in Chile has been maintained over time, reduces the effectiveness of vaccination campaigns, and the need to include BVDV- $1 j$ viruses when designing a vaccine for future use in Chile.

\section{Conclusions}

The results of this study showed that the genetic profile of BVDV in Chilean cattle is composed of the subgenotypes BVDV-1a, BVDV-1b, and BVDV-1j, with BVDV-1b and BVDV- $1 j$ as the predominant subgenotypes.

The Chilean BVDV-1b viruses grouped into a single cluster, apart from the viruses present in Argentina and Brazil, countries geographically close to Chile. This process of local evolution may have generated antigenic differences between the Chilean BVDV-1b viruses and the viruses used in vaccines.

The high increase shown over time of BVDV-1j viruses in Chile, and the low genetic diversity in the E2 gene, the most variable protein of the virus, both among Chilean BVDV- $1 j$ viruses and with BVDV- $1 j$ viruses present in other regions of the world, suggests that BVDV- $1 j$ is an emergent group of viruses in cattle in Chile, and since they show important antigenic differences with BVDV-1a and BVDV-1b viruses used in commercial vaccines, their inclusion in the vaccines used in Chile should be evaluated.

\section{Abbreviations \\ 5'UTR: 5' Untranslated Region; ATCC: American type culture collection; BVDV: Bovine Viral Diarrhea Virus; BVDV-1: Bovine Viral Diarrhea Virus species 1; BVDV-1a: Bovine Viral Diarrhea Virus subgenotype 1a; BVDV-1b: Bovine Viral Diarrhea Virus subgenotype 1b; BVDV-1j: Bovine Viral Diarrhea Virus subgenotype 1j; BVDV-2: Bovine Viral Diarrhea Virus species 2; DEPC: Diethyl pyrocarbonate; DIF: Direct immunofluorescence; E2: Glycoprotein E2; FITC: Fluorescein isothiocyanate; MDBK: Madin-Darby bovine kidney cell; nDomC: Near Domain C; PAAS: Pattern of amino acid substitutions; PCR: Polymerase Chain Reaction; PI: Persistently infected; PID: Percentage identities; RT-PCR: Reverse transcription polymerase chain reaction}

\section{Acknowledgements}

We are grateful to Dr. Sagar Goyal (University of Minnesota, USA) for providing the MDBK cell line.

\section{Funding}

This study was funded by the Comisión Nacional de Investigación Científica y Tecnológica (CONICYT) from the Chilean Government, project FONDECYTRegular 1060581, granted to José Pizarro-Lucero. 


\section{Availability of data and materials}

The datasets and materials used and/or analysed during the current study available from the corresponding author on reasonable request. All DNA sequences have been submitted in GenBank (http:// www.ncbi.nlm.nih.gov/genbank/) under the accession numbers indicated in Table 1.

\section{Authors' contributions}

AD: Collected samples, performed experiments, and analyzed data. FI: Collected samples, performed experiments, and analyzed data. MC: Performed experiments, analyzed data, and supervised the study. JPL: Performed experiments, analyzed data, wrote the manuscript, and supervised and supported the study. All authors read and approved the manuscript.

\section{Ethics approval}

Animal procedures were carried out according to good veterinary practices following the guidelines of the Manual of Standards for Biosafety (2008) from the National Commission for Scientific and Technological Research (CONICYTChile), the Institutional Animal Care and Use Committees of the Universidad de Chile, and the revised Animals (Scientific Procedures) Act 1986.

\section{Consent for publication}

Not applicable

\section{Competing interests}

The authors declare that they have no competing interests.

\section{Publisher's Note}

Springer Nature remains neutral with regard to jurisdictional claims in published maps and institutional affiliations.

\section{Received: 4 June 2018 Accepted: 3 October 2018} Published online: 19 October 2018

\section{References}

1. Baker JC. Bovine viral diarrhea virus: a review. J Am Vet Med Assoc. 1987; 190:1449-57.

2. Brownlie J, Clarke MC, Howard CJ, Pocock DH. Pathogenesis and epidemiology of bovine virus diarrhoea virus infection of cattle. Ann Rech Vet. 1987;18:157-66.

3. Radostits OM, Littlejohns IR. New concepts in the pathogenesis, diagnosis and control of disease caused by the bovine viral diarrhea virus. Can Vet J. 1988;29:513-28.

4. Rebhun WC, French TW, Perdrizet JA, Dubovi EJ, Dill SG, Karcher LF. Thrombocytopenia associated with acute bovine virus diarrhea infection in cattle. J Vet Intern Med. 1989:3:42-6.

5. Corapi W, Elliott RD, French TW, Arthur DG, Bezek DM, Dubovi EJ. Thrombocytopenia and hemorrhages in veal calves infected with bovine viral diarrhea virus. J Am Vet Med Assoc. 1990;196:590-6.

6. Pellerin C, Hurk JVD, Lecomte J, Tijssen P. Identification of a new group of bovine viral diarrhea virus strains associated with severe outbreaks and high mortalities. Virology. 1994;203:260-8.

7. Simmonds P, Becher P, Bukh J, Gould EA, Meyers G, Monath T, Muerhoff S, Pletnev A, Rico-Hesse R, Smith DB. Stapleton JT and ICTV report consortium. ICTV virus taxonomy profile: Flaviviridae. J Gen Virol. 2017;98:2-3.

8. Yeşilbağ $\mathrm{K}$, Alpay $\mathrm{G}$, Becher P. Variability and global distribution of subgenotypes of bovine viral diarrhea virus. Viruses. 2017;9(6):E128. https://doi.org/10.3390/v9060128.

9. Vilcek S, Paton DJ, Durkovic B, Strojny L, Ibata G, Moussa A, Loitsch A, Rossmanith W, Vega S, Scicluna MT, Palfi V. Bovine viral diarrhoea virus genotype 1 can be separated into at least eleven genetic groups. Arch Virol. 2001;146:99-115.

10. Flores EF, Gil LHGV, Botton SA, Weiblen R, Ridpath JF, Kreutz LC, Pilati C, Driemeyer D, Moojen V, Wendelstein AC. Clinical, pathological and antigenic aspect of bovine viral diarrhea (BVDV) type 2 isolates identified in Brazil. Vet Microbiol. 2000;77:175-83.

11. Jackova A, Novackova M, Pelletier C, Audeval C, Gueneau E, Haffar A, Petit E, Rehby L, Vilcek S. The extended genetic diversity of BVDV-1: typing of BVDV isolates from France. Vet Res Commun. 2008;32:7-11.
12. Nagai M, Hayashi M, Itou M, Fukutomi T, Akashi H, Kida H, Sakoda Y Identification of new genetic subtypes of bovine viral diarrhea virus genotype 1 isolated in Japan. Virus Genes. 2008;36(1):135-9.

13. Xue F, Zhu YM, Li J, Zhu LC, Ren XG, Feng JK, Shi HF, Gao YR. Genotyping of bovine viral diarrhea viruses from cattle in China between 2005 and 2008. Vet Microbiol. 2010;143(2-4):379-83.

14. Giammarioli M, Ceglie L, Rossi E, Bazzucchi M, Casciari C, Petrini S, De Mia GM. Increased genetic diversity of BVDV-1: recent findings and implications thereof. Virus Genes. 2015;50:147-51.

15. Wolfmeyer A, Wolf G, Beer M, Strube W, Hehnem HR, Schmeer N, Kaaden OR. Genomic (5'UTR) and serological differences among German BVDV field isolates. Arch Virol. 1997;142:2049-57.

16. Nagai $M$, Sato $M$, Nagano $H$, Pang $H$, Kong $X$, Murakami T, Ozawa $T$, Akashi $H$. Nucleotide sequence homology to bovine viral diarrhea virus 2 (BVDV 2) in the $5^{\prime}$ untranslated region of BVDVs from cattle with mucosal disease or persistent infection in Japan. Vet Microbiol. 1998;60: $271-6$.

17. Jones $L R$, Zandomeni R, Webwe EL. Genetic typing of bovine viral diarrhea virus isolates from Argentina. Vet Microbiol. 2001:81:367-75.

18. Couvreur B, Letellier C, Collard A, Quenon P, Dehan P, Hamers C, Pastoret PP, Kerkhofs P. Genetic and antigenic variability in bovine viral diarrhea virus (BVDV) isolates from Belgium. Virus Res. 2002;85:17-28.

19. Vilcek S, Greiser-Wilke I, Durkovic B, Obritzhauser W, Deutz A, Kofer J. Genetic diversity of recent bovine viral diarrhoea viruses from the southeast of Austria (Styria). Vet Microbiol. 2003;91:285-91.

20. Pizarro-Lucero J, Celedón M-O, Aguilera M, de Calisto A. Molecular characterization of pestiviruses isolated from bovines in Chile. Vet Microbiol. 2006;115:208-17.

21. Bauermann FV, Ridpath JF. HoBi-like viruses - the typical 'atypical bovine pestivirus'. Anim Health Res Rev. 2015;16(1):64-9.

22. Celedón MO, Vargas C, Salinas A, Casanova A, Ibarra L, Berríos P. Prevalencias serológicas para el virus diarrea viral bovina y de la rinotraqueitis infecciosa bovina en predios lecheros de la Región Metropolitana de Chile. Av Cs Vet. 1996;11:75-80.

23. Celedón MO, Palacios L, Pizarro J, Ibarra L. Prevalencia de anticuerpos seroneutralizantes para el virus de la diarrea viral bovina en ganado de carne de la región Metropolitana de Chile. Av Cs Vet. 1997;12:98-100.

24. Mahony TJ, McCarthy FM, Gravel JL, Corney B, Young PL, Vilcek S. Genetic analysis of bovine viral diarrhoea viruses from Australia. Vet Microbiol. 2005;106(1-2):1-6.

25. OIE. Manual of Diagnostic Tests and Vaccines for Terrestrial Animals 2017. Chapter 24.7. http://www.oie.int/fileadmin/Home/eng/Health_standards/ tahm/2.04.07_BVD.pdf. Accessed 02 March 2018.

26. INE. http://www.ine.cl/estadisticas/censos/censo-agropecuario-y-forestal2007. Accessed 30 March 2018.

27. Vilcek $S$, Herring AJ, Herring JA, Nettleton PF, Lowings JP, Paton DJ. Pestiviruses isolated from pigs, cattle and sheep can be allocated into at least three genogroups using polymerase chain reaction and restriction endonuclease analysis. Arch Virol. 1994;136:309-23.

28. Edgar RC. MUSCLE: multiple sequence alignment with high accuracy and high throughput. Nucleic Acids Res. 2004;32:1792-7.

29. Kumar S, Stecher G, Tamura K. MEGA7: molecular evolutionary genetics analysis version 7.0 for bigger datasets. Mol Biol Evol. 2016:33:1870-4.

30. Muhire BM, Varsani A, Martin DP. SDT: a virus classification tool based on pairwise sequence alignment and identity calculation. PLoS One. 2014;9(9):e108277. https://doi.org/10.1371/journal.pone. 0108277.

31. Salgado R, Hidalgo-Hermoso E, Pizarro-Lucero J. Detection of persistent pestivirus infection in pudú (Pudu puda) in a captive population of artiodactyls in Chile. BMC Vet Res. 2018. https://doi.org/10.1186/s12917-018-1363-x.

32. Pizarro-Lucero J, Celedón MO, Navarro C, Ortega R, González D. Identification of a pestivirus isolated from a free-ranging pudu (Pudu puda) in Chile. Vet Rec. 2005;157:292-4

33. Aguirre IM, Quezada MP, Celedón MO. Antigenic variability in bovine viral diarrhea virus (BVDV) isolates from alpaca (Vicugna pacos), llama (Lama glama) and bovines in Chile. Vet Microbiol. 2014;168:324-30.

34. Pecora A, Malacari DA, Ridpath JF, Perez Aguirreburualde MS, Combessies G, Odeón AC, Romera SA, Golemba MD, Wigdorovitz A. First finding of genetic and antigenic diversity in $1 \mathrm{~b}-\mathrm{BVDV}$ isolates from Argentina. Res Vet Sci. 2014;96:204-12.

35. Silveira S, Weber MN, Mósena ACS, da Silva MS, Streck AF, Pescador CA, Flores EF, Weiblen R, Driemeier D, Ridpath JF, Canal CW. Genetic diversity of 
brazilian bovine pestiviruses detected berween 1995 and 2014. Transbound Emerg Dis. 2017;64(2):613-23.

36. Ridpath JF. Practical significance of heterogeneity among BVDV strains: impact of biotype and genotype on U.S. control programs. Prev Vet Med. 2005; $72: 17-30$

37. Tajima M, Dubovi EJ. Genetic and clinical analyses of bovine viral diarrhea virus isolates from dairy operations in the United States of America. J Vet Diagn Investig. 2005;17(1):10-5.

38. Hornberg A, Fernández SR, Vogl C, Vilcek S, Matt M, Fink M, Köfer J, Schöpf K. Genetic diversity of pestivirus isolates in cattle from Western Austria. Vet Microbiol. 2009;135(3-4):205-13.

39. Arias P, Orlich M, Prieto M, Cedillo S, Thiel H-J, Alvarez M, Becher P. Genetic heterogeneity of bovine viral diarrhoea viruses from Spain. Vet Microbiol. 2003;96:327-36.

40. Tajima M. The prevalent genotypes of bovine viral diarrhea virus in Japan, Germany and the United States of America. Jpn J Vet Res. 2006;54(2-3):129-34.

41. Giammarioli M, Pellegrini C, Casciari C, Rossi E, De Mia GM. Genetic diversity of bovine viral diarrhea virus 1: Italian isolates clustered in at least seven subgenotypes. J Vet Diagn Investig. 2008;20(6):783-8.

42. Canal CW, Strasser M, Hertig C, Masuda A, Peterhans E. Detection of antibodies to bovine viral diarrhea virus (BVDV) and characterization of genomes of BVDV from Brazil. Vet Microbiol. 1998;63:85-97.

43. Becher P, Avalos-Ramirez R, Orlich M, Rosales SC, Konig M, Schweizer M, Stalder $\mathrm{H}$, Schirrmeier $\mathrm{H}$, Thiel $\mathrm{H}$-J. Genetic and antigenic characterization of novel pestivirus genotypes: implications for classification. Virology. 2003;311:96-104.

Ready to submit your research? Choose BMC and benefit from:

- fast, convenient online submission

- thorough peer review by experienced researchers in your field

- rapid publication on acceptance

- support for research data, including large and complex data types

- gold Open Access which fosters wider collaboration and increased citations

- maximum visibility for your research: over $100 \mathrm{M}$ website views per year

At $\mathrm{BMC}$, research is always in progress.

Learn more biomedcentral.com/submissions 